\title{
Intravenous aminophylline and cerebral blood flow in preterm infants
}

\author{
Maura McDonnell, N K Ives, P L Hope
}

\begin{abstract}
The effect of aminophylline on cerebral blood flow (CBF) was studied in 10 preterm infants who were receiving $6.2 \mathrm{mg} / \mathrm{kg}$ intravenously over 20 minutes followed by a maintenance infusion. CBF was measured intermittently using near infrared spectroscopy. Heart rate, blood pressure, oxygen saturation, and transcutaneously measured carbon dioxide tension $\left(\mathrm{TcPCO}_{2}\right)$ were recorded continuously. Aminophylline administration was associated with a fall in CBF from a median of 15.9 $\mathrm{ml} / 100 \mathrm{~g} / \mathrm{min}$ to $11.2 \mathrm{ml} / 100 \mathrm{~g} / \mathrm{min}$. Median fall in CBF was $4.1 \mathrm{ml} / 100 \mathrm{~g} / \mathrm{min}$ (95\% confidence interval 1.7 to 6.5 ). Heart rate rose and $\mathrm{TcPCO}_{2}$ fell in all infants, median fall being $0.66 \mathrm{kPa}$. The reduction in CBF was greater than would be expected on the basis of the modest fall in $\mathrm{TcPCO}_{2}$.
\end{abstract}

Aminophylline and other methylxanthines are frequently used in the neonatal period and have been reported to cause reduction in cerebral blood flow. ' We have used near infrared spectroscopy (NIRS) to study cerebral haemodynamics and oxygenation before and after intravenous loading of preterm infants with aminophylline, according to the usual regimen for treatment of apnoea of prematurity on our unit.

NIRS is a non-invasive optical technique which provides continuous cotside measurement of the amounts of oxyhaemoglobin, reduced haemoglobin, and oxidised cytochrome aa 3 in the light path between two optodes applied to either side of the infant's head. ${ }^{2}$ Each of these three chromophores has a characteristic absorption spectrum for near infrared light. Light at six discrete wavelengths is transmitted from laser diodes to the head along fibreoptic cables. A sensitive photomultiplier detects the small amounts of light transmitted across the head, and the attenuation at different wavelengths can be used to calculate chromophore concentrations.

A transient increase in the infant's inspired oxygen concentration will cause a bolus of oxyhaemoglobin to enter the brain at a rate which is determined by cerebral blood flow (CBF) and can be measured by NIRS. CBF can be quantified in this way, using the method described by Edwards et al. ${ }^{3}$

\section{Patients and methods}

Ten preterm infants (gestation 23-31 weeks, median 26) were studied at 4-28 (median 9) days of age. Median birth weight was $830 \mathrm{~g}$, range 519-2056 g. Seven of the infants were receiving mechanical ventilation, one was in headbox oxygen, and two were being treated with continuous positive airways pressure.

Aminophylline was prescribed for the treatment of apnoea of prematurity or to assist weaning from ventilatory assistance. A loading dose of $6.2 \mathrm{mg} / \mathrm{kg}$ body weight was given intravenously over 20 minutes and was followed by a maintenance infusion of $4.4 \mathrm{mg} / \mathrm{kg} /$ day. This regimen was recommended by Jones and Baillie on the basis of pharmacokinetic studies, and was calculated to give a serum concentration of $28-66 \mu \mathrm{mol} / 1$ one hour after loading. ${ }^{4}$

Oxygen saturation was measured by a pulse oximeter on the right hand working in beat to beat mode, and mean arterial blood pressure was measured through an umbilical or peripheral areterial cannula using a Hewlett-Packard pressure transducer. Heart rate, transcutaneous carbon dioxide tension $\left(\mathrm{TcPCO}_{2}\right)$, oxygen saturation, and mean arterial blood pressure were monitored continuously throughout the 2-4 (median 3) hour period of each study. Physiological measurements were stored on disc at 2-20 second intervals using the data storage system of the NIR spectrometer.

The near infrared measurements were made using the NIR-1000 (Hamamatsu Photonics KK) spectrometer. Optodes were applied to each temporal region, kept in place by an elasticated bandage, and covered by a light occluding hat which prevented contamination of the near infrared signal by external light. CBF was measured using a change in oxyhaemoglobin as a tracer. By the Fick principle, CBF can be calculated as the ratio of oxyhaemoglobin accumulated in the brain to the quantity introduced into the brain during a time period less than cerebral transit time (which is approximately 10 seconds). After a period when the oxyhaemoglobin signal and oxygen saturation were stable (with a saturation of $88-89 \%$ ), the inspired oxygen concentration was suddenly increased in order to induce a transient increase in saturation of $5-8 \%$. Cerebral oxyhaemoglobin and oxygen saturation were recorded at two second intervals during this manoeuvre for subsequent calculation of $\mathrm{CBF}$.

CBF measurements were made on one to four (median three) occasions during the 135 minutes before drug infusion, and on one to five (median three) occasions in the 110 minutes after drug infusion. All infants were clinically stable during the period of the study. CBF values were not available 'on line' during the recording period. The near infrared and physiological data
Oxford OX3 9DU.

Accepted 2 December 1991 
stored on disc in the spectrometer were transferred to a microcomputer spreadsheet for quantitative analysis at a later time. The data recorded during each brief period of induced rise in oxygen saturation were inspected, and all episodes in which data fitted a prospectively determined set of criteria were analysed and a CBF measurement determined. Measurements of physiological variables were taken during the periods of CBF measurement and later used in statistical analysis. Mean values of readings from each infant in the period before the drug were compared with mean values from the period after the drug was given using Wilcoxon signed ranks test for paired non-parametric data.

\section{Results}

Median CBF in the predrug period was 15.9 $\mathrm{ml} / 100 \mathrm{~g} / \mathrm{min}$ ( $95 \%$ confidence interval $(\mathrm{CI}) 13.5$ to $17 \cdot 7$ ) and median $\mathrm{CBF}$ in the postdrug period was $11 \cdot 2 \mathrm{ml} / 100 \mathrm{~g} / \mathrm{min}$. Eight infants showed a fall in $C B F$, one infant no change and one showed a $0.9 \mathrm{ml} / 100 \mathrm{~g} / \mathrm{min}(6.9 \%)$ rise. The median fall in CBF was $4.1 \mathrm{ml} / 100 \mathrm{~g} / \mathrm{min}(95 \%$ CI $1 \cdot 7$ to $6 \cdot 5)$, or $28 \cdot 9 \%(95 \%$ CI $12 \cdot 3$ to $37 \cdot 7)$. Figure 1A shows the individual data points. The fall in CBF was significant on paired testing at $\mathrm{p}<0.01$.

Figure 1B shows that heart rate rose in all infants $(\mathrm{p}<0.01)$, by a median of 12 beats $/ \mathrm{min}$ $(95 \%$ CI 9 to $19 \cdot 2)$.

Figure 1C shows that a fall in $\mathrm{TcPCO}_{2}$ was demonstrated in all infants $(\mathrm{p}<0 \cdot 01)$. Median fall was $0.66 \mathrm{kPa}(95 \% \mathrm{CI} 0.40$ to 0.84$)$. There was no consistent change in mean arterial blood pressure after aminophylline infusion (fig 1D).

If the changes in CBF (dCBF) after aminophylline were completely due to the changes in carbon dioxide tension $\left(\mathrm{dPCO}_{2}\right)$, then a quantitative relationship between $\mathrm{dCBF}$ and $\mathrm{dPCO}_{2}$ would be expected. However, there was no significant correlation between $\mathrm{dCBF}$ and $\mathrm{dPCO}_{2}$, either expressed in absolute terms (correlation coefficient $r=0.57, n=10, N S$ ) or as a fraction of resting values $(r=0 \cdot 49, n=10, N S)$.
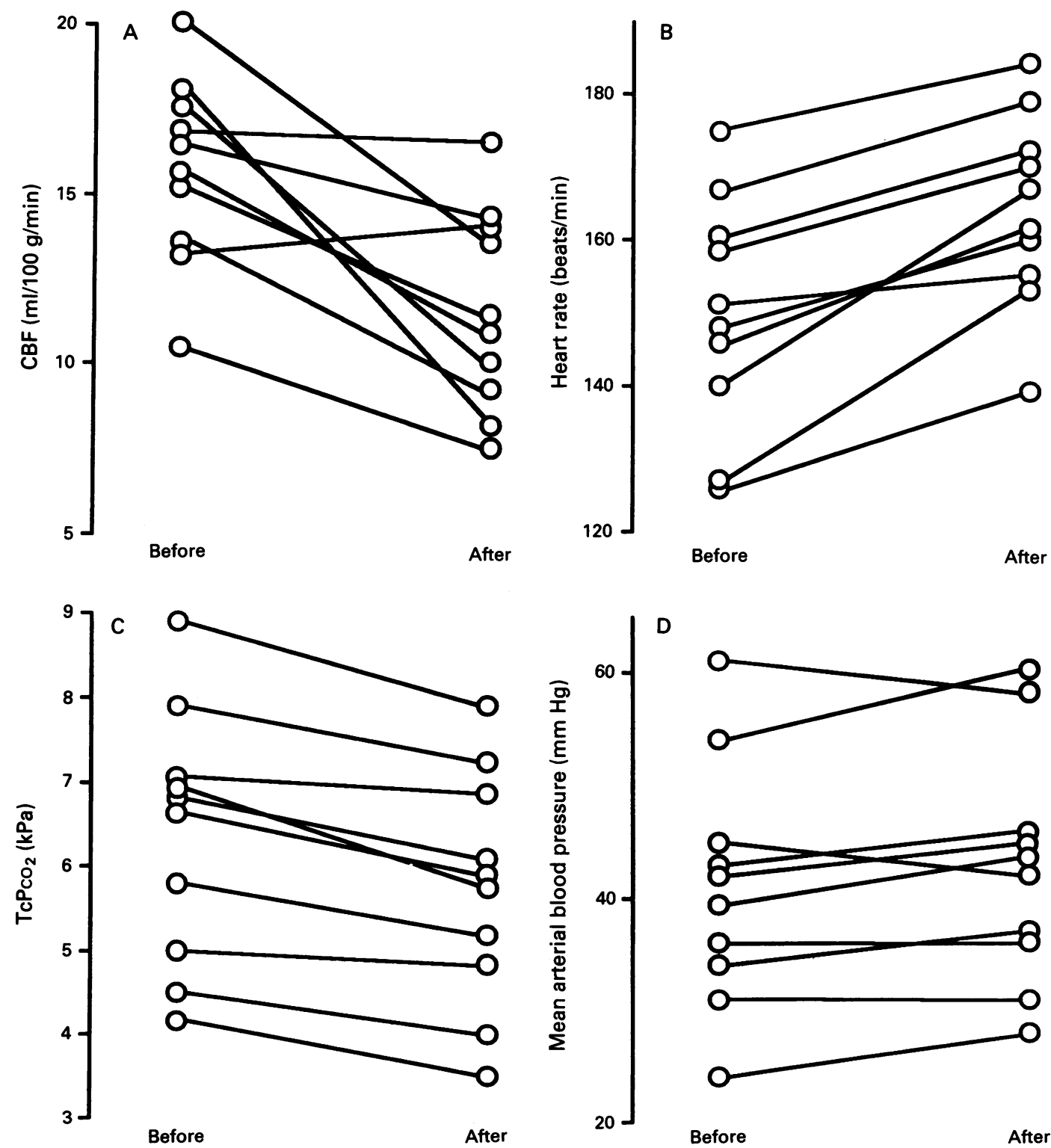

Paired values of $(A)$ cerebral blood flow, $(B)$ heart rate, $(C) T_{c P C O}$, and $(D)$ mean arterial blood pressure before and after aminophylline infusion. $(A),(B)$, and $(C)$ show significant changes: $p<0 \cdot 01$, using Wilcoxon signed ranks test; $(D)$ shows no significant change. 


\section{Discussion}

Aminophylline and other methylxanthines are commonly used for the treatment of apnoea of prematurity, and to assist weaning of low birthweight infants from mechanical ventilation. Preterm infants treated with methylxanthines show increased alveolar ventilation, ${ }^{5}$ decrease in the incidence of apnoeic episodes, ${ }^{5}$ and higher cardiac output due to increases in both heart rate and stroke volume. ${ }^{6}$ These diverse effects are attributed to adenosine receptor antagonism, as very little phosphodiesterase inhibition occurs at therapeutic serum concentrations. ${ }^{7}$ As adenosine is known to be a cerebral vasodilator, aminophylline may be expected to cause vasoconstriction and reduction in $\mathrm{CBF} .^{7}$

Wechsler et al in 1950 were the first group to show reduction in CBF after aminophylline administration. ${ }^{8}$ Using the Kety-Schmidt method they showed a $25 \%$ fall in CBF of adults receiving an intravenous loading dose. The effect of methylxanthines on cerebral blood flow velocity (CBFV) of preterm infants has been measured by Doppler ultrasound in four studies. Rosenkrantz and Oh showed a $17 \%$ reduction in CBFV two hours after a $5 \mathrm{mg} / \mathrm{kg}$ bolus of aminophylline ${ }^{9}$ which they attributed to a concomitant fall in $\mathrm{PCO}_{2}$. Ghai et al found no change in $\mathrm{PCO}_{2}$ or $\mathrm{CBFV}$ in 13 preterm infants studied 50 hours after starting enteral therapy. ${ }^{10}$ Two recent studies have shown no effect of systemic doses of caffeine on CBFV in preterm infants, ${ }^{11} 12$ although one of these studies ${ }^{11}$ showed a significant fall in $\mathrm{PCO}_{2}$. However, Doppler studies are difficult to interpret because CBFV may not reliably reflect CBF in this clinical situation when heart rate, blood pressure, $\mathrm{PCO}_{2}$, and cerebral vessel diameter may all be changing. Pryds et al, using intravenous xenon ${ }^{133}$ clearance to measure $\mathrm{CBF}$, reported a $13.8 \%$ reduction in $\mathrm{CBF}$ but unaltered visual evoked responses, one hour after $10 \mathrm{mg} / \mathrm{kg}$ intravenous aminophylline. ${ }^{1}$

NIRS can be used to determine cerebral blood flow with minimal patient disturbance. Since the description of the technique ${ }^{3}$ there have been two reports validating the results of the NIR technique against xenon clearance methods. ${ }^{1314}$ Both NIRS and xenon clearance give surprisingly low values for CBF in the newborn, but they are consistent with values reported by Volpe et al using positron emission tomography. ${ }^{15}$

Nine infants in this present study had two or more measurements of CBF before the dose of aminophylline and the mean coefficient of variation of $\mathrm{CBF}$ measurement during this clinically stable period was $19 \%(95 \%$ CI $12 \cdot 8-25 \cdot 9)$. This coefficient is high and presumably reflects, at least in part, methodological limitations, but does not alter the significance of the changes in CBF seen on paired testing after aminophylline.

There was a small but consistent fall in $\mathrm{PCO}_{2}$, but we do not consider this to be the full explanation for the considerable fall in CBF. Reported values for carbon dioxide reactivity of the cerebral circulation of preterm infants vary considerably. Pryds et al recently showed, using intravenous xenon ${ }^{133}$, a $28 \cdot 9 \%$ change per $\mathrm{kPa}$ change in $\mathrm{PCO}_{2} .{ }^{16}$ Using this value the fall in $\mathrm{PCO}_{2}$ we have reported in this study would be expected to result in a fall in CBF of $19 \%$, whereas a median decrease of $29 \%$ was actually observed. In addition, if decreased $\mathrm{PCO}_{2}$ was the sole mechanism for the fall in $\mathrm{CBF}$, there should be some relationship between the extent to which $\mathrm{PCO}_{2}$ and $\mathrm{CBF}$ fall in individual infants, which was not demonstrated. It appears, therefore, that an intravenous loading dose of aminophylline leads to a fall in CBF which cannot be entirely explained by a small decrease in $\mathrm{PCO}_{2}$.

A decrease of $\mathrm{CBF}$, and hence cerebral oxygen delivery, will generally be compensated for by increased oxygen extraction resulting in a lower cerebral venous oxygen tension. There may be no clinical sequelae to considerable falls in CBF such as shown here with aminophylline treatment, or previously reported with indomethacin. ${ }^{17}$ However, if cerebral oxygen delivery is already compromised in a sick preterm infant with hypotension and impaired oxygenation, further reduction of $\mathrm{CBF}$ of the magnitude reported in this study could potentially have serious sequelae.

We are very grateful to Hamamatsu Photonics (KK) for the generous lon of the NIR 1000 spectrometer, to Andrew Wilkinson for allowing us to study his patients, to Mr P Sutton for technical help, and to the nursing staff and parents for their cooperation.

1 Pryds O, Schneider S. Aminophylline reduces cerebral blood flow in stable, preterm infants without affecting the visual evoked potential. Eur 7 Pediatr 1991;150:366-9.

2 Wyatt JS, Cope M, Delpy DT, Wray S, Reynolds EOR. Quantitation of cerebral oxygenation and haemodynamics in sick newborn infants by near infrared spectroscopy. Lancet 1986;ii: $1063-6$.

3 Edwards AD, Wyatt JS, Richardson C, Delpy DT, Cope M Reynolds EOR. Cotside measurement of cerebral blood flow in ill preterm infants by near infrared spectroscopy. flow in ill preterm in

4 Jones RAK, Baillie E. Dosage schedule for intravenous aminophylline in apnoea of prematurity, based on pharmacokinetic studies. Arch Dis Child 1979;54:190-3.

5 Davi MJ, Sankaran K, Simons KJ, Simons FER, Seshia MM, Rigatto $H$. Physiologic changes induced by theophylline in the treatment of apnea in preterm infants. $\mathcal{F}$ Pediat 1978;92:91-5.

6 Walther FJ, Sims ME, Siassi B, Wu PYK. Cardiac outpu changes secondary to theophylline therapy in preterm infants. F Pediatr 1986;109:874-6.

7 Rall TW. Central nervous system stimulants: the methylxanthines. In: Goodman L, Gilman A, eds. The pharmacological basis of therapeutics. 7th Ed. New York: Macmillan, logical

8 Wechsler RL, Kleiss LM, Kety SS. The effects of intravenously administered aminophylline on cerebral circuvenously administered aminophylline on cerebral circu-

9 Rosenkrantz ES, Oh W. Aminophylline reduces cerebral blood flow velocity in low birthweight infants. Am $\mathcal{F}$ Dis bhild 1984;138:489-91.

10 Ghai V, Raju TNK, Kim SY, McCullough KM. Regional cerebral blood flow velocity after aminophylline therapy in premature newborn infants. F Pediatr 1989;114:870-3.

11 Van Bel F, Van de Bor M, Stijnen T, Baan J, Ruys JH. Does caffeine affect cerebral blood flow in the preterm infant? Acta Paediatr Scand 1989;78:295-9.

12 Saliba E, Autret E, Gold F, Bloc D, Pourcelot L, Laugier J. Effect of caffeine on cerebral blood flow velocity in preterm infants. Biol Neonate 1989;56:198-203.

13 Bucher H-U, Edwards AD, Lipp AE, Duc G. Comparison between 133-Xenon clearance and near infrared spectroscopy for estimation of cerebral blood flow. Pediatr Res 1991:30:630.

14 Skov L, Pryds O, Greisen G. Estimating cerebral blood flow in newborn infants: comparison of near infrared spectroscopy and 133-xenon clearance Pediatr Res 1991;30: scopy
630.

15 Volpe JJ, Herschovitch P, Perlman JM, Raichle ME. Positron emission tomography in the newborn: extensive impairment of regional cerebral blood flow with intraventricular heforic ventricular hemorrhage and hem.

16 Pryds O, Andersen GE, Friis-Hansen B. Cerebral blood flow reactivity in spontaneously breathing, preterm infants sh AD, Watt JS, Richards Scan 1990;9:391-6.

17 Edwards AD, Wyatt JS, Richardson C, el al. Effects of indomethacin on cerebral haemodynamics in very preterm 